\title{
Deteksi Dini Penurunan Status Fungsi Kognitif dan Edukasi Terkait Upaya Pencegahannya pada Pasien Stroke Iskemik di Rumah Sakit Islam Siti Hajar Mataram
}

\author{
Herpan Syafii Harahap*1, Yanna Indrayana ${ }^{2}$, Hendra Susana Putra ${ }^{3}$, Indah Retnowati ${ }^{3}$, Asriningrum $^{4}$, \\ Christabella Natalia Wijaya ${ }^{5}$, Qisthinadia Hazhiyah Setiadi ${ }^{5}$, Silmina Alifiya ${ }^{6}$, Fatarosdiana $^{6}$ \\ ${ }^{1}$ Departemen Neurologi, Fakultas Kedokteran Universitas Mataram, Mataram, Indonesia; \\ ${ }^{2}$ Departemen Kardiologi, Fakultas Kedokteran Universitas Mataram, Mataram, Indonesia; \\ ${ }^{3}$ Laboratorium Terpadu, Fakultas Kedoketran Universitas Mataram, Mataram, Indonesia; \\ ${ }^{4}$ Bagian Saraf, Rumah Sakit Islam Siti Hajar, Mataram, Indonesia; \\ ${ }^{5}$ Rumah Sakit Umum Daerah Provinsi Nusa Tenggara Barat, Mataram, Indonesia; \\ ${ }^{6}$ Dokter Internship Rumah Sakit Bhayangkara, Mataram, Indonesia
}

Article history

Received: 05-02-2021

Revised: 09-03-2021

Accepted: 11-03-2021

*Corresponding Author:

Herpan Syafii Harahap,

Departemen Neurologi,

Fakultas Kedokteran

Universitas Mataram, Mataram,

Indonesia;

Email:

herpanharahap@unram.ac.id
Abstract: Decreased cognitive function is one of the important complications of stroke, especially in ischemic strokes. The prevalence of cognitive decline among ischemic stroke patients itself is currently above $70 \%$. Early detection of ischemic stroke-associated cognitive decline and its risk factors can provide a good clinical outcome in the patients. Thus, the event aimed at early detection of cognitive decline in ischemic stroke patients and education related to its prevention are very important. A total of 51 ischemic stroke outpatients within the first 3 months of stroke onset visiting Neurology Department of Siti Hajar Islamic Hospital, Mataram, were able to complete their full participation in this event. Most of the patients had a mean age of 54 years, male gender, high school education, within the first 4 weeks from stroke onset, and had hypertension as well as dyslipidemia. Patient characteristics that were significantly associated with the frequency of ischemic stroke-associated cognitive decline were age, hypertension and atrial fibrillation ( $\mathrm{p}<0.05)$. All patients and their accompanying family members showed high enthusiasm. This early detection for cognitive decline is beneficial for ischemic stroke patients and the education provided in this event is useful in increasing their knowledge regarding steps that must be taken to prevent ischemic stroke-associated cognitive decline.electronic document is the template "for your abtract paper consisting of background, goals, methods and results.

Keywords: Stroke; dementia; cognitive; promotive; preventive

Abtrak: Penurunan fungsi kognitif merupakan salah satu komplikasi penting dari stroke, terutama pada stroke iskemik. Prevalensi penurunan kognitif pada pasien stroke iskemik sendiri saat ini diatas $70 \%$. Deteksi dini terhadap penurunan fungsi kognitif terkait stroke iskemik dan faktor-faktor yang menyertainya dapat memberikan luaran klinis yang baik pada pasiennya. Dengan demikian, kegiatan pengabdian kepada masyarakat yang ditujukan untuk deteksi dini penurunan kognitif pada pasien stroke iskemik dan edukasi terkait upaya pencegahannya sangat penting untuk dilakukan. Sebanyak 51 pasien stroke iskemik dewan waktu awitan stroke iskemik 3 bulan pertama yang datang ke Poliklinik Saraf RSI Siti Hajar Mataram mampu menyelesaikan partisipasinya secara penuh dalam kegiatan ini. Sebagian besar pasien memiliki rerata usia 54 tahun, sebagian besar laki-laki, memiliki pendidikan SMA, awitan stroke dalam 4 minggu pertama, dan memiliki 
hipertensi dan dislipidemia. Karakteristik pasien yang berhubungan secara signifikan dengan frekuensi terjadinya penurunan fungsi kognitif terkait stroke iskemik antara lain usia pasien, hipertensi, dan atrial fibrilasi $(\mathrm{p}<0.05)$. Seluruh pasien dan anggota keluarga penyerta menunjukkan antusiasme yang tinggi. Kegiatan deteksi dini penurunan fungsi kognitif ini sangat bermanfaat bagi pasien stroke iskemik dan edukasi yang diberikan bermanfaat dalam meningkatkan pengetahuan mereka terkait langkah-langkah yang harus dilakukan untuk mencegah terjadinya penurunan fungsi kognitif terkait stroke iskemik.

Kata Kunci: Stroke; demensia; kognitif; promotif; preventif

\section{PENDAHULUAN}

Penurunan fungsi kognitif merupakan salah satu komplikasi penting dari stroke, terutama pada stroke iskemik. Prevalensi penurunan kognitif pada pasien stroke iskemik sendiri saat ini sekitar 70\% (Lesniak et al., 2007; Renjen et al., 2015). Penelitian terdahulu di Kota Mataram menunjukkan bahwa prevalensi penurunan fungsi kognitif pada pasien stroke iskemik lebih tinggi, yaitu sebesar $80 \%$ (Harahap et al., 2021). Penurunan fungsi kognitif terkait stroke iskemik tersebut dapat muncul dalam spektrum yang luas, mulai dari penurunan fungsi kognitif ringan sampai dengan berat. Penurunan fungsi kognitif yang ringan umumnya bersifat samar dan tidak dikenali oleh pasien dan/atau keluarganya. Namun ternyata penurunan fungsi kognitif pada tahap inilah yang memiliki prognosis yang baik dan progresivitasnya untuk menjadi lebih berat masih bisa dihambat. Perbaikan fungsi kognitif pada tahap ini secara teori terkait dengan neuroplastisitas di otak yang optimal yang umumnya terjadi dalam kurun waktu 3 bulan pertama dari awitan stroke (Alia et al., 2017). Pada penurunan fungsi kognitif yang lebih berat (demensia), pada umumnya ditemukan pada pasien stroke lebih dari 3 bulan sampai beberapa tahun pertama dari awitan stroke, pasien mengalami penurunan bermakna dari kapasitas fungsionalnya yang bersifat menetap dan memiliki ketergantungan yang tinggi kepada anggota keluarganya (Rohde et al., 2016). Pengobatan yang diberikan pada tahap ini sulit untuk menghasilkan perbaikan klinis yang bermakna. Pasien stroke iskemik yang pada tahap awal memiliki status fungsi kognitif normal, masih dapat mengalami penurunan fungsi kognitif dalam kurun waktu beberapa tahun setelah awitan stroke (del Ser et al., 2005).

Penurunan fungsi kognitif yang ditemukan pada pasien stroke iskemik dapat merupakan dampak langsung dari stroke yang dialaminya atau akibat dari keberadaan faktor-faktor risiko untuk terjadinya stroke dan penurunan fungsi kognitif yang menyertainya. Beberapa karakteristik demografik dan klinik pasien yang diketahui turut berkontribusi untuk terjadinya penurunan fungsi kognitif pada pasien stroke antara lain adalah usia lanjut, tingkat pendidikan rendah, awitan terjadinya stroke, merokok, hipertensi, diabetes melitus, kegemukan, dislipidemia, dan atrial fibrilasi (Zulkifly et al., 2016; Lo et al., 2019). Usia lanjut dan hipertensi merupakan faktor risiko utama untuk terjadinya gangguan kognitif pasca stroke dan demensia vaskuler (Kalaria et al., 2016). Penelitian terdahulu menunjukkan bahwa tingkat pendidikan pasien stroke iskemik merupakan faktor risiko penting untuk terjadinya gangguan kognitif pada populasi pasien stroke di Kota Mataram (Harahap et al., 2021). Identifikasi faktor-faktor risiko stroke yang dapat dimodifikasi, terutama merokok, hipertensi, diabetes melitus, obesitas, dislipidemia, dan atrial fibrilasi dan edukasi terkait penatalaksanaannya merupakan bagian penting dari strategi penatalaksanaan gangguan kognitif terkait stroke iskemik.

Dengan demikian, perlu dilakukan pengabdian kepada masyarakat yang ditujukan untuk deteksi dini penurunan kognitif pada pasien stroke iskemik dan edukasi terkait penatalaksanaan 
penurunan fungsi kognitif terkait stroke iskemik dan faktor-faktor risiko vaskuler penyertanya pada pasien stroke iskemik di Kota Mataram. Deteksi dini yang dilakukan dalam kegiatan pengabdian masyarakat ini ditujukan terhadap pasien stroke iskemik yang memiliki awitan penyakit stroke dalam kurun waktu 3 bulan pertama. Kegiatan pengabdian kepada masyarakat ini dilaksanakan pada masa pandemi Covid-19. Dengan demikian, pemeriksaan fungsi kognitif dan edukasi pasien dalam kegiatan ini dilaksanakan dengan menerapkan protokol pencegahan penularan infeksi Covid-19.

\section{METODE}

Kegiatan pengabdian kepada masyarakat ini dilaksanakan di Poliklinik Saraf Rumah Sakit Islam (RSI) Siti Hajar Mataram selama Bulan Februari 2019 - Mei 2020. Pasien yang menjadi sasaran dalam kegiatan pengabdian masyarakat ini adalah pasien stroke iskemik yang masih dalam kurun waktu 3 bulan pertama dari awitan stroke, memiliki tingkat pendidikan minimal sekolah dasar, dan tidak mengalami afasia. Setiap pasien stroke iskemik di poliklinik yang memenuhi kriteria tersebut diminta kesediaannya untuk dilakukan pemeriksaan fungsi kognitif. Mereka diminta datang pada hari pemeriksaan yang ditentukan dengan didampingi oleh salah satu anggota keluarga dengan menggunakan masker yang sudah terstandar. Sehari sebelum pemeriksaan, status rekam medis pasien yang akan diperiksa juga akan disiapkan di poliklinik.

Pada hari dilakukan pemeriksaan fungsi kognitif, dilakukan pengambilan data fungsi kognitif pasien stroke iskemik dengan menggunakan instrumen Mini-mental State Examination (MMSE). Pada pemeriksaan ini, pasien diminta untuk mengikuti instruksi yang ada dalam instrumen MMSE tersebut yang dibacakan dan dipandu oleh pemeriksa. Instrumen ini memiliki rentang skor 0-30 dan status kognitif pasien dikategorikan normal bila diperoleh skor MMSE 24-30 dan menurun bila diperoleh skor MMSE 0-23. Pada pemeriksaan fungsi kognitif tersebut, skor MMSE dan status kognitif pasien dicatat. Dalam pemeriksaan ini juga dilakukan pengambilan data karakteristik demografik dan klinik pasien. Data karakteristik demografik pasien yang diambil antara lain usia, jenis kelamin, dan tingkat pendidikan. Tingkat pendidikan pasien dikategorikan menjadi Sekolah Dasar (SD), Sekolah Menengah Pertama (SMP), Sekolah Menengah Atas (SMA), dan Sarjana. Data karakteristik klinik yang diambil dalam penelitian ini antara lain waktu awitan stroke, status merokok, hipertensi, diabetes melitus, indeks massa tubuh (IMT), dislipidemia, dan atrial fibrilasi. Waktu awitan stroke dalam kegiatan ini dikategorikan menjadi $\leq 4$ minggu, 5-8 minggu, dan 9-12 minggu. IMT pasien stroke iskemik dikategorikan menjadi normal (IMT $<25 \mathrm{~kg} / \mathrm{m} 2$ ), kegemukan (IMT $25-29.9 \mathrm{~kg} / \mathrm{m} 2$ ), dan obesitas (IMT $\geq 30 \mathrm{~kg} / \mathrm{m} 2$ ). Data-data karakteristik demografik dan klinik tersebut diatas diperoleh melalui wawancara dengan pasien dan anggota keluarga dan dari rekam medik pasien yang telah dipersiapkan sehari sebelumnya.

Setelah pemeriksaan status fungsi kognitif dan pengambilan data karakteristik demografik dan klinik pasien stroke iskemik selesai dilakukan, pasien diberikan informasi mengenai hasil evaluasi status fungsi kognitifnya dan faktor-faktor risiko penyerta yang dimilikinya. Pasien stroke iskemik yang memiliki status fungsi kognitif menurun diberikan edukasi terkait upaya yang harus dilakukan untuk memperbaiki fungsi kognitifnya, mempertahankan fungsionalnya sehari-hari tetap baik, dan mencegah progresivitas penurunan fungsi kognitifnya, baik secara farmakologis maupun nonfarmakologis. Pasien stroke iskemik yang masih memiliki status fungsi kognitif normal juga diedukasi terkait pentingnya penanganan faktor-faktor risiko yang dimilikinya, terutama faktor-faktor risiko 
yang dapat dimodifikasi, sebagai upaya preventif untuk mencegah terjadinya penurunan fungsi kognitif terkait stroke iskemik dan terjadinya serangan ulang stroke iskemik.

Pada tahap akhir, dilakukan analisis statistik untuk menilai kebermaknaan hubungan antara karakteristik-karakteristik demografik dan klinik pasien stroke iskemik dengan frekuensi penurunan fungsi kognitif. Data-data terkait karakteristik demografik, klinik, dan status fungsi kognitif dari seluruh partisipan kegiatan ini akan disajikan dalam tabel distribusi frekuensi. Data terkait hubungan antara karakteristik demografik dan klinik dan status kognitif pasien-pasien tersebut akan dianalisis secara statistik dengan menggunakan uji Man-Whitney dan kai-kuadrat, dengan nilai $\mathrm{p}<0.05$ digunakan sebagai acuan untuk menunjukkan kebermaknaan hubungan antar variabel-variabel tersebut.

\section{HASIL DAN PEMBAHASAN}

Dalam kurun waktu 4 bulan kegiatan ini, didapatkan sebanyak 51 pasien stroke iskemik yang memiliki waktu awitan stroke iskemik 3 bulan pertama yang datang ke Poliklinik Saraf RSI Siti Hajar Mataram. Sebagian besar pasien tersebut merupakan pasien stroke iskemik yang telah menjalani rawat inap di RSI Siti Hajar dan dijadwalkan kontrol di poliklinik saraf tersebut. Seluruh pasien tersebut berpartisipasi penuh dalam kegiatan pengabdian masyarakat ini, termasuk dalam mengerjakan tugastugas kognitif yang ada dalam instrumen MMSE (Gambar 1). Partisipasi penuh dari seluruh pasien stroke iskemik dan anggota keluarga yang mendampinginya tersebut dalam kegiatan ini menunjukkan tingkat kesadaran yang tinggi dari mereka terhadap pentingnya deteksi dini gangguan kognitif terkait stroke iskemik dan edukasi terkait penatalaksanaannya.
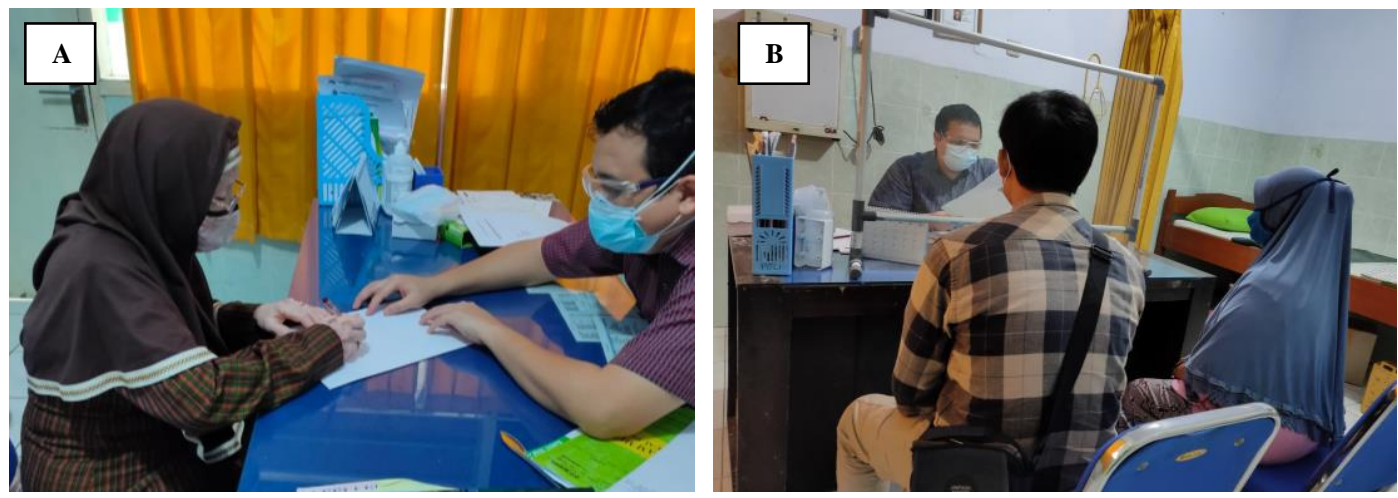

Gambar 1. Dokumentasi kegiatan deteksi dini deteksi dini penurunan fungsi kognitif pada pasien stroke iskemik dan edukasi terkait upaya pencegahannya. A. Pemeriksaan status fungsi kognitif pasien. B. Edukasi kepada pasien dan anggota keluarga yang mendampinginya.

Terkait dengan karakteristik demografiknya, pasien stroke iskemik yang turut berpartisipasi dalam kegiatan pengabdian masyarakat ini memiliki rerata usia 54 tahun, sebagian besar laki-laki, dan memiliki pendidikan SMA. Pada tabel tersebut juga bisa dilihat bahwa tingkat pendidikan Sarjana juga memiliki proporsi yang cukup tinggi, yaitu tertinggi kedua setelah SMA. Terkait dengan karakteristik kliniknya, sebagian besar pasien memiliki awitan stroke 4 minggu pertama dan memiliki hipertensi dan dislipidemia sebagai faktor risikonya. Pasien stroke iskemik dengan faktor-faktor risiko 
lainnya, antara lain merokok, diabetes melitus, kegemukan dan obesitas, dan atrial fibrilasi memiliki proporsi yang lebih kecil (Tabel 1).

Tabel 1. Karakteristik pasien stroke iskemik di poli saraf RSI Siti Hajar Mataram

\begin{tabular}{|c|c|c|}
\hline Kategori & Sub-kategori & $\begin{array}{c}\text { Rerata } \pm \text { SD atau } \\
\text { Jumlah }(\%) \\
(\mathrm{n}=51)\end{array}$ \\
\hline Usia dalam tahun & & $54.2 \pm 6.8$ \\
\hline \multirow[t]{2}{*}{ Jenis kelamin } & Laki-laki & $36(70.6)$ \\
\hline & Perempuan & $15(29.4)$ \\
\hline \multirow[t]{4}{*}{ Tingkat pendidikan } & Sekolah Dasar & $8(15.7)$ \\
\hline & Sekolah Menengah Pertama & $7(13.7)$ \\
\hline & Sekolah Menengah Atas & $21(41.2)$ \\
\hline & Sarjana & $15(29.4)$ \\
\hline \multirow[t]{3}{*}{ Onset stroke } & $\leq 4$ minggu & $29(56.8)$ \\
\hline & $5-8$ minggu & $11(21.6)$ \\
\hline & 9-12 minggu & $11(21.6)$ \\
\hline \multirow[t]{2}{*}{ Merokok } & $\mathrm{Ya}$ & $21(41.2)$ \\
\hline & Tidak & $30(58.8)$ \\
\hline \multirow[t]{2}{*}{ Hipertensi } & Ya & $44(86.3)$ \\
\hline & Tidak & $7(13.7)$ \\
\hline \multirow[t]{2}{*}{ Diabetes } & Ya & $19(37.3)$ \\
\hline & Tidak & $32(62.7)$ \\
\hline \multirow[t]{3}{*}{ IMT } & Normal $(<25 \mathrm{~kg} / \mathrm{m} 2)$ & $29(56.9)$ \\
\hline & Kegemukan $(25-29.9 \mathrm{~kg} / \mathrm{m} 2)$ & $20(39.2)$ \\
\hline & Obesitas $(\geq 30 \mathrm{~kg} / \mathrm{m} 2)$ & $2(3.9)$ \\
\hline \multirow[t]{2}{*}{ Dislipidemia } & $\mathrm{Ya}$ & $30(58.8)$ \\
\hline & Tidak & $21(41.2)$ \\
\hline \multirow[t]{2}{*}{ Atrial fibrilasi } & $\mathrm{Ya}$ & $6(11.8)$ \\
\hline & Tidak & $45(88.2)$ \\
\hline Skor MMSE & & $24.8 \pm 3.4$ \\
\hline \multirow[t]{2}{*}{ Status kognitif } & Normal & $39(76.5)$ \\
\hline & Menurun & $12(23.5)$ \\
\hline
\end{tabular}

$\mathrm{SD}=$ standard of deviation; IMT=indeks massa tubuh; MMSE=Mini-mental State Examination.

Rerata usia yang masuk dalam kategori dewasa muda ( $<60$ tahun) dari pasien stroke iskemik dalam kegiatan ini dan mayoritas jenis kelamin laki-laki menunjukkan adanya ancaman penurunan produktivitas kerja dari pasien-pasien tersebut akibat penurunan fungsi kognitif terkait stroke, baik pada masa saat ini maupun dalam beberapa tahun kedepan. Apabila terjadi, penurunan produktivitas kerja tersebut akan berpotensi untuk menyebabkan ketergantungan pasien yang tinggi terhadap anggota keluarga yang mengasuhnya. Apabila penurunan fungsi kognitif yang timbul nantinya semakin progresif menjadi lebih berat, maka pasien-pasien tersebut dalam beberapa tahun kedepan akan menjadi beban ekonomi dan sosial bagi keluarga dan sistem kesehatan yang ada (Rohde et al., 2016). Dengan demikian, kegiatan pengabdian masyarakat ini mendapatkan sasaran partisipan yang tepat untuk dilakukan deteksi dini gangguan kognitif terkait stroke iskemik dan edukasi untuk memperbaiki luaran klinisnya, yaitu tercapainya kapasitas fungsional yang optimal. Dalam kegiatan ini, baik pasien stroke iskemik maupun anggota keluarga yang mendampinginya menunjukkan antusiasme yang tinggi (Gambar 1). Secara umum, anggota keluarga yang menyertai pasien tersebut dalam kegiatan ini, yang hampir seluruhnya merupakan anak dari pasien sendiri yang mengasuh 
pasien tersebut setiap hari, secara aktif bertanya mengenai langkah-langkah apa saja yang harus mereka lakukan agar pasien yang mereka rawat tidak jatuh sampai pada kondisi demensia. Mereka menyadari betul bahwa jika kondisi pasien yang mereka rawat tersebut menjadi demensia, maka hal ini juga akan memperberat tugas mereka. Dengan hilangnya kapasitas fungsional pasien, maka segala bentuk aktivitas kognitif sehari-hari pasien tersebut akan sangat bergantung kepada pengasuhnya. Mereka juga sadar, mengingat mereka juga memiliki aktivitas lain untuk dirinya dan keluarganya yang tidak bisa ditinggalkan, terutama dalam hal pemenuhan kebutuhan ekonomi, maka kondisi demensia tersebut akan meningkatkan risiko terlantarnya pasien tersebut.

Pada Tabel 1 juga bisa dilihat bahwa terdapat proporsi yang besar untuk pasien stroke yang memiliki tingkat pendidikan yang baik (SMA dan Sarjana) dan memiliki awitan stroke yang relatif baru ( $\leq 4$ minggu pertama dari terjadinya stroke). Tingkat pendidikan yang baik tersebut merupakan modal penting dalam upaya tatalaksana gangguan kognitif terkait stroke iskemik karena beberapa alasan. Pertama, tingkat pendidikan yang baik menggambarkan cognitive reserve yang baik dari pasien tersebut, yang memungkinkan pasien-pasien tersebut untuk dapat belajar lebih cepat dalam mengompensasi penurunan fungsi kognitifnya sedemikian rupa sehingga kapasitas fungsional mereka lebih cepat pulih (Barulli and Stern, 2013; Jung et al., 2018). Kedua, kegiatan edukasi yang dilakukan dalam kegiatan ini membutuhkan kemampuan pasien-pasien dalam memahami informasi dan instruksi yang diberikan dengan baik. Dengan tingkat pendidikan pasien yang baik tersebut dan ditunjang dengan cognitive reserve yang dimilikinya, maka program edukasi yang disampaikan dalam kegiatan ini diharapkan bisa mencapai tingkat keberhasilan yang tinggi. Awitan stroke yang relatif baru (4 minggu pertama dari awitan stroke) memberikan rentang waktu yang cukup lebar untuk mendapatkan perbaikan fungsi kognitif terkait neuroplastisitas di otak (Alia et al., 2017). Dengan penyampaian informasi yang relatif sederhana terkait cara pencegahan terjadinya gangguan kognitif terkait stroke iskemik, upaya untuk menjaga fungsi kognitif agar tetap normal, upaya untuk memperbaiki fungsi kognitif yang menurun, dan upaya memperlambat progresivitasnya dalam kegiatan ini, pasien-pasien stroke iskemik dan anggota keluarga yang mendampinginya menunjukkan antusiasme yang tinggi. Mereka aktif dalam bertanya atau mengonfirmasi kesesuaian antara pemahaman yang mereka miliki dengan informasi yang diberikan dalam kegiatan edukasi ini.

Pada tabel 2, dapat dilihat bahwa karakteristik pasien stroke iskemik yang berhubungan secara signifikan dengan frekuensi terjadinya gangguan fungsi kognitif pada pasien stroke iskemik yang menjadi partisipan kegiatan ini adalah usia pasien, hipertensi, dan atrial fibrilasi $(\mathrm{p}<0.05)$. Dari ketiga variabel yang berhubungan secara bermakna dengan frekuensi penurunan status fungsi kognitif tersebut, hipertensi dan atrial fibrilasi merupakan karakteristik klinik pasien yang dapat dimodifikasi. Namun demikian, terlepas dari hasil analisis secara statistik tersebut, keberadaan karakteristik klinik lainnya, seperti merokok, diabetes melitus, kegemukan, dan dislipidemia, bukan berarti tidak penting dan tidak membutuhkan penatalaksanaan secara baik. Penatalaksanaan terhadap semua karakteristik klinik yang juga merupakan faktor-faktor risiko vaskuler tersebut juga merupakan salah satu upaya penting dalam pencegahan terhadap terjadinya serangan stroke berulang maupun penurunan fungsi kognitif terkait stroke iskemik yang sangat penting untuk dilakukan (Zulkifly et al., 2016). Diantara semua faktor risiko tersebut, pemberian informasi terkait penatalaksanaan hipertensi dan atrial fibrilasi dalam kegiatan ini lebih ditekankan sampai keluarga pasien benar-benar memahami hal tersebut. Edukasi terkait penatalaksanaan secara farmakologis dan non-farmakologis terhadap faktor-faktor risiko vaskuler tersebut kepada pasien dan pengasuh pasien dalam kegiatan ini juga dilakukan dengan 
sesederhana mungkin agar dipahami dengan baik oleh mereka. Dalam kegiatan edukasi terkait hal ini, pasien dan anggota keluarga yang mendampinginya juga menunjukkan antusiasme yang tinggi.

Tabel 2. Hubungan antara karakteristik pasien stroke iskemik dan status kognitifnya

\begin{tabular}{|c|c|c|c|}
\hline \multirow[t]{3}{*}{ Karakteristik } & \multicolumn{2}{|c|}{ Status kognitif } & \multirow{3}{*}{ lai $\mathrm{p}$} \\
\hline & \multirow[b]{2}{*}{$(n=39)$} & Menur & \\
\hline & & un $(n=12)$ & \\
\hline Usia dalam tahun & $55.1 \pm 6.9$ & $51.2 \pm 6.0$ & $0.042^{\mathrm{a} *}$ \\
\hline \multicolumn{4}{|l|}{ Jenis kelamin } \\
\hline Laki-laki & $29(80.6)$ & $7(19.4)$ & \multirow[t]{2}{*}{$0.237^{\mathrm{b}}$} \\
\hline Perempuan & $10(66.7)$ & $5(33.3)$ & \\
\hline \multicolumn{4}{|l|}{ Tingkat pendidikan } \\
\hline Sekolah Dasar & $5(62.5)$ & $3(37.5)$ & \multirow[t]{4}{*}{$0.196^{\mathrm{b}}$} \\
\hline Sekolah Menengah Pertama & $4(57.1)$ & $3(42.9)$ & \\
\hline Sekolah Menengah Atas & $16(76.2)$ & $5(23.8)$ & \\
\hline Sarjana & $14(93.3)$ & $1(6.7)$ & \\
\hline \multicolumn{4}{|l|}{ Onset stroke } \\
\hline$\leq 4$ minggu & $22(75.9)$ & $7(24.1)$ & \multirow[t]{3}{*}{$0.908^{\mathrm{b}}$} \\
\hline $5-8$ minggu & $9(81.8)$ & $2(18.2)$ & \\
\hline 9-12 minggu & $8(80.0)$ & $2(20.0)$ & \\
\hline \multicolumn{4}{|l|}{ Merokok } \\
\hline Ya & $15(71.4)$ & $6(28.6)$ & \multirow[t]{2}{*}{$0.351^{\mathrm{b}}$} \\
\hline Tidak & $24(80.0)$ & $6(20.0)$ & \\
\hline \multicolumn{4}{|l|}{ Hipertensi } \\
\hline Ya & $36(81.8)$ & $8(18.2)$ & \multirow[t]{2}{*}{$0.044^{\mathrm{b} *}$} \\
\hline Tidak & $3(42.9)$ & $4(57.1)$ & \\
\hline \multicolumn{4}{|l|}{ Diabetes melitus } \\
\hline $\mathrm{Ya}$ & $14(73.7)$ & $5(26.3)$ & \multirow[t]{2}{*}{$0.486^{\mathrm{b}}$} \\
\hline Tidak & $25(78.1)$ & $7(21.9)$ & \\
\hline \multicolumn{4}{|l|}{ Indeks massa tubuh } \\
\hline Normal & $22(75.9)$ & $7(24.1)$ & \multirow[t]{3}{*}{$0.724^{\mathrm{b}}$} \\
\hline Kegemukan & $15(75.0)$ & $5(25.0)$ & \\
\hline Obesitas & $2(100.0)$ & $0(0.0)$ & \\
\hline \multicolumn{4}{|l|}{ Dislipidemia } \\
\hline $\mathrm{Ya}$ & $24(80.0)$ & $6(20.0)$ & \multirow[t]{2}{*}{$0.351^{\mathrm{b}}$} \\
\hline Tidak & $15(71.4)$ & $6(28.6)$ & \\
\hline \multicolumn{4}{|l|}{ Atrial fibrilasi } \\
\hline $\mathrm{Ya}$ & $2(33.3)$ & $4(66.7)$ & \multirow[t]{2}{*}{$0.022^{\mathrm{b} *}$} \\
\hline Tidak & $37(82.2)$ & $8(17.8)$ & \\
\hline
\end{tabular}

${ }^{\mathrm{a} U j i}$ Mann-Whitney; ${ }^{\mathrm{b} U j i}$ kai-kuadrat, *Bermakna $(\mathrm{p}<0.05)$

Dengan melihat manfaat kegiatan pengabdian kepada masyarakat ini yang cukup besar terhadap peningkatan status kesehatan pasien stroke iskemik, maka kegiatan ini diharapkan dapat terus dilanjutkan. Perlu dilakukan evaluasi status fungsi kognitif pasien stroke iskemik secara berkala setiap 3-6 bulan untuk memastikan bahwa status fungsi kognitif mereka tetap normal atau pada mereka yang mengalami penurunan fungsi kognitif, progresivitasnya dapat dicegah atau diperlambat. Dengan evaluasi secara berkala tersebut, maka tujuan dari upaya promotif dan preventif dari kegiatan ini dapat tercapai. 


\section{KESIMPULAN DAN SARAN}

Dalam kegiatan pengabdian kepada masyarakat ini, frekuensi pasien stroke iskemik yang datang ke Poliklinik Saraf RSI Siti Hajar Mataram yang mengalami penurunan status fungsi kognitif cukup tinggi. Dari faktor-faktor risiko yang dapat diidentifikasi, usia, hipertensi, dan atrial fibrilasi merupakan faktor-faktor risiko yang secara bermakna berhubungan dengan tingginya frekuensi penurunan status fungsi kognitif tersebut. Kegiatan edukasi terkait upaya pencegahan penurunan status fungsi kognitif pada pasien-pasien tersebut sangat dibutuhkan, baik oleh pasien-pasien itu sendiri maupun oleh anggota keluarga yang mengasuhnya sehari-hari. Perlu dilakukan evaluasi status fungsi kognitif pasien-pasien tersebut secara berkala untuk mengevaluasi apakah fungsi kognitif tersebut tetap normal, mengalami perbaikan atau justru mengalami progresivitas menjadi demensia.

\section{Ucapan Terima Kasih}

Penulis menyampaikan terima kasih kepada Lembaga Penelitian dan Pengabdian kepada Masyarakat (LPPM) Universitas Mataram dan pihak Rumah Sakit Islam (RSI) Siti Hajar Mataram yang turut memfasilitasi pelaksanaan kegiatan ini.

\section{DAFTAR PUSTAKA}

Lesniak, M., Bak, T., Czepiel, W., Seniow, J., Czlonkowska, A. 2008. Frequency and prognostic value of cognitive disorders in stroke patients. Dementia and Geriatric Cognitive Disorders. vol 26, hal 356-363.

Renjen, P. N., Gauba, C., Chaudhari, D. 2015. Cognitive impairment after stroke. Cureus. vol 7 no 9 , hal e335.

Harahap, H. S., Indrayana, Y., Putri, S. A. 2021. Relationship between level of education and poststroke cognitive status in hospital-based ischemic stroke survivors. Malang Neurology Journal. vol 7 no 1, hal 1-6.

Alia, C., Spalletti, C., Lai, S., Panarese, A., Lamola, G., Bertolucci, F., et al. 2017. Neuroplastic Changes Following Brain Ischemia and their Contribution to Stroke Recovery: Novel Approaches in Neurorehabilitation. Frontiers in Cellular Neuroscience. vol 11, hal 76.

Rohde, D., Williams, D., Gaynor, E., Bennett, K., Dolan, E., Callaly, E., et al. 2017. Secondary prevention and cognitive function after stroke: a study protocol for a 5-year follow-up of the ASPIRE-S cohort. BMJ Open. vol 7, hal e014819.

del Ser, T., Barba, R., Morin, M. M., Domingo, J., Cemillan, C., Pondal, M., et al. 2005. Evolution of Cognitive Impairment After Stroke and Risk Factors for Delayed Progression. Stroke. vol 36, hal 2670-52005.

Zulkifly, M. F. M., Ghazali, S. E., Din, N. C., Singh, D. K. A., Subramaniam, P. 2016. A Review of Risk Factors for Cognitive Impairment in Stroke Survivors. The Scientific World Journal. vol 2016, hal 3456943.

Lo, J. W., Crawford, J. D., Desmond, D. W., Godefroy, O., Jokinen, H., Mahinrad, S., et al. 2019. Profile of and risk factors for poststroke cognitive impairment in diverse ethnoregional groups. Neurology. vol 93, hal e2257-e2271. 
Kalaria, R. N., Akinyemi, R., Ihara, M. 2016. Stroke injury, cognitive impairment and vascular dementia. Biochimica et Biophysica Acta - Molecular Basis of Disease. vol 1862 no 5, hal 915-925.

Barulli, D., and Stern, Y. 2013. Efficiency, capacity, compensation, maintenance, plasticity: emerging concepts in cognitive reserve. Trends in Cognitive Sciences. vol 17 no 10, hal 502-509.

Jung, N. Y., Cho, H., Kim, Y. J., Kim, H. J., Lee, J. M., Park, S., et al. 2018. The impact of education on cortical thickness in amyloid-negative subcortical vascular dementia: cognitive reserve hypothesis. Alzheimer's Research and Therapy. vol 10, hal 103. 